\title{
SULPHUR AND HEAVY METAL POLLUTION IN URBAN SNOW: MULTI-ELEMENTAL ANALYTICAL TECHNIQUES AND INTERPRETATIONS
}

by

\author{
S. Landsberger
}

(Nuclear Reactor, McMaster University, Hamilton, Ontario L8S 4K1, Canada)

and R.E. Jervis

(Department of Chemical Engineering and Applied Chemistry, University of Toronto, Toronto, Ontario M5S 1A4, Canada)

\section{ABSTRACT}

Three multi-elemental techniques (neutron activation analysis, proton-induced $\mathrm{X}$-ray emission and inductively coupled plasma-atomic emission spectrometry) are described in terms of their special advantages in determining sulphur and heavy metal pollution in urban snow. Environmental analytical interpretations, including wash-out factors, enrichment factors, inter-elemental correlations, mobilization factors, and toxicity potential, are also discussed.

\section{INTRODUCTION}

One of the most important and vexing challenges in the field of public health is the proper investigation and subsequent control of air, water and soil pollution in industrialized urban cities and rural areas. Polluting substances released to the environment can have important toxicological effects on aquatic, animal and plant ecosystems. These substances can and do undergo long-range transport through the atmosphere. The primary pathway back to Earth is by means of precipitation, both wet and dry, of ten at distances hundreds to thousands of kilometers downwind from the original sources.

Among recent environmental studies the measurement of trace elements in fine particles and in wet atmospheric deposition has received increased attention because of their potential toxic effects (Jeffries and Snyder 1981, Lindberg 1981, Tanaka and others 1981, Thornton and others 1981, Hamilton and Chatt 1982). Sulphur has recently received a significant amount of attention because it is one of the main precursors of acid precipitation. However, the co-contaminants of acid snow are also considered to be worthy of investigation. Elements such as vanadium, manganese, mercury, lead, nickel, copper, zinc, arsenic, cadmium and selenium, all of which can be emitted with sulphur, are all potentially toxic, even at quite low concentrations. Of ten studies have been initiated of which the toxicologist, the environmental and the analytical scientists have not been aware, and they may not have seen the significance of each other's work. Certain new analytical techniques, pushed to their detection limits, have of ten been considered too imprecise or time-consuming by one or other of the workers and new methods often have difficulty in being accepted as being useful and reliable. Nuclear analytical techniques are prime examples.

While the chemistry of polar snows has received attention for many years (Murozumi and others 1969, Boutron and others 1972, Weiss and others 1978, Boutron 1980 , and many references in the above papers), detailed analysis of urban snow has not benefited from such intense investigations.

Investigation of trace contaminants in urban snow has been much less frequent for the obvious reason that snowfall does not occur of ten enough in many places to warrant useful environmental studies. However, a study of

snow composition can be potentially just as fruitful as that from rainfall. This is especially true for countries such as Canada (Barrie and Walmsley 1978, Barrie 1979 and 1980, Jeffries and Snyder 1981, Jervis and others 1982, 1983, Landsberger and others 1983[a], 1983[b]), Norway (Forland and Gjessing 1975, Johannessen and others 1977, Dovland and Eliassen 1976, Wright and Dovland 1977, Johannessen and Henriksen 1978), USA (Struempler 1976, Moore and others 1978, Thornton and others 1981), Poland (Zajac and Grodzinska 1981), and Germany (Schrimpff and others 1979) where winters are long and snowfalls are abundant. However, in many of these reports only a few pollutants were investigated and environmental analytical interpretations were scarce while studies were not always focused on urban snow. This, coupled with the fact that laboratory procedures varied significantly for each study, makes intercomparisons hard to achieve (e.g. insoluble/soluble fractions).

Here we describe the results for three multi-elemental analytical techniques to determine sulphur and heavy metal pollution in urban snow: neutron activation analysis (NAA), proton-induced X-ray emission (PIXE) and inductively coupled plasma-atomic emission spectroscopy (ICP-AES). Possible environmental interpretations, including soluble/insoluble fractions, wash-out factors, enrichment factors, inter-elemental

TABLE I. SOME TYPICAL DETECTION LIMITS OF PRECIPITATION SAMPLES, UNCONCENTRATED AND FREEZE DRIED, USING NEUTRON ACTIVATION ANALYSIS

Element $\begin{gathered}\text { Detection limit Element } \\ \left(\mu \mathrm{g}^{-1}\right)\end{gathered} \quad \begin{gathered}\text { Detection limit } \\ \left(\mu \mathrm{g} \mathrm{1}^{-1}\right)\end{gathered}$

$\begin{array}{lclc}\mathrm{Na} & 32 & \mathrm{As} & 5 \\ \mathrm{Mg} & 25 & \mathrm{Br} & 2 \\ \mathrm{Al} & 7 & \mathrm{Sr} & 10 \\ \mathrm{Cl} & 10 & \mathrm{Ag} & 0.2 \\ \mathrm{~K} & 25 & \mathrm{In} & 0.05 \\ \mathrm{Sc} & 0.2 & \mathrm{Sb} & 1 \\ \mathrm{Ca} & 20 & \mathrm{I} & 5 \\ \mathrm{Cr} & 1 & \mathrm{Ba} & 5 \\ \mathrm{Ti} & 10 & \mathrm{Cs} & 1 \\ \mathrm{~V} & 0.05 & \mathrm{La} & 0.05 \\ \mathrm{Mn} & 0.2 & \mathrm{Ce} & 0.1 \\ \mathrm{Fe} & 20 & \mathrm{Eu} & 0.05 \\ \mathrm{Co} & 1 & \mathrm{Sm} & 0.05 \\ \mathrm{Ni} & 20 & \mathrm{Lu} & 0.05 \\ \mathrm{Zn} & 5 & \mathrm{~W} & 1 \\ \mathrm{Cu} & 15 & \mathrm{Au} & 0.05 \\ \mathrm{Se} & 1 & \mathrm{Th} & 0.05\end{array}$




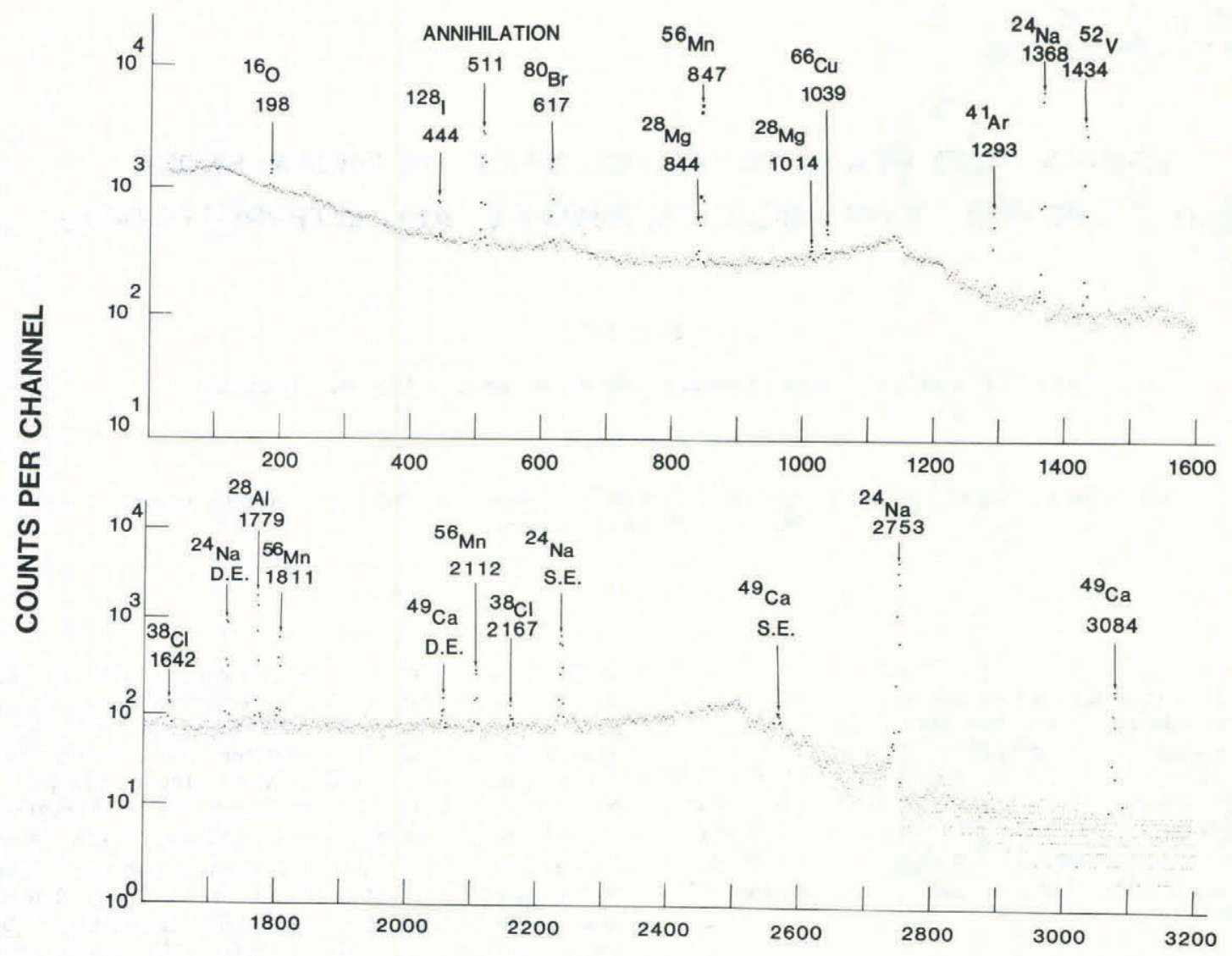

\section{CHANNEL NUMBER}

Fig.1. Typical spectrum of preconcentrated snow soluble portion using instrumental NAA (Jervis and others 1983).

correlations, mobilization factors and toxicity potential are also presented. A large part of this paper has arisen from a snow study carried out by the author and co-workers (Landsberger and others 1983[a]).

\section{MULTI-ELEMENTAL TECHNIQUES}

\subsection{Neutron activation analysis (NAA)}

Although some important rain studies have employed NAA techniques (Bogen 1974, Salmon 1975, Schuyster and others 1978, Beavington and Cawse 1979, Slanina and others 1979, Hamilton and Chatt 1982), urban snow studies have largely been neglected.

Barrie $(1979,1980)$ using NAA in conjunction with other analytical techniques, determined the transport, transformation and removal of atmospheric particulate matter in Alberta, Canada. The ambient concentrations, deposition patterns and deposition rates of several elements in air and snow were studied.

Landsberger and others (1983[a], 1983[b]) and Jervis and others $(1982,1983)$ have successfully employed instrumental neutron activation methods to undertake an in-depth study of urban snow. A typical gamma-ray spectrum can be seen in Figure 1 while some typical detection limits in rain or snow samples are shown in Table I. The detection limits are a combination of unconcentrated and/or freeze-dried methods.

In particular NAA can determine halides and rare-earth elements. These two groups of elements are usually not capable of being detected by many existing methods in a non-destructive fashion.

2.2. Proton-induced $\mathrm{X}$-ray emission (PIXE)

PIXE methods are now well accepted for many environmental investigations. At present it appears that only one group from Canada (Jervis and others 1982, 1983, Landsberger and others 1983[a], 1983[b]) have extensively used PIXE techniques to study soluble and insoluble fractions of either urban, remote or polar snow. Typical $X$-ray spectra for snow analysis are shown in
Figures 2 and 3 . The above-mentioned references discuss the salient features of PIXE.

Of prime importance is the detection of total sulphur, lead and nickel with excellent sensitivities. Typical detection limits are seen in Table II.

TABLE II. TYPICAL DETECTION LIMITS OF SNOW SOLUBLE AND PARTICULATE PORTION USING PIXE METHOD (Landsberger and others 1983[a])

Element Soluble portion Particulate portion $\left(\mu \mathrm{g}^{-1}\right) \quad\left(\mu \mathrm{g}^{-1}\right)$ 


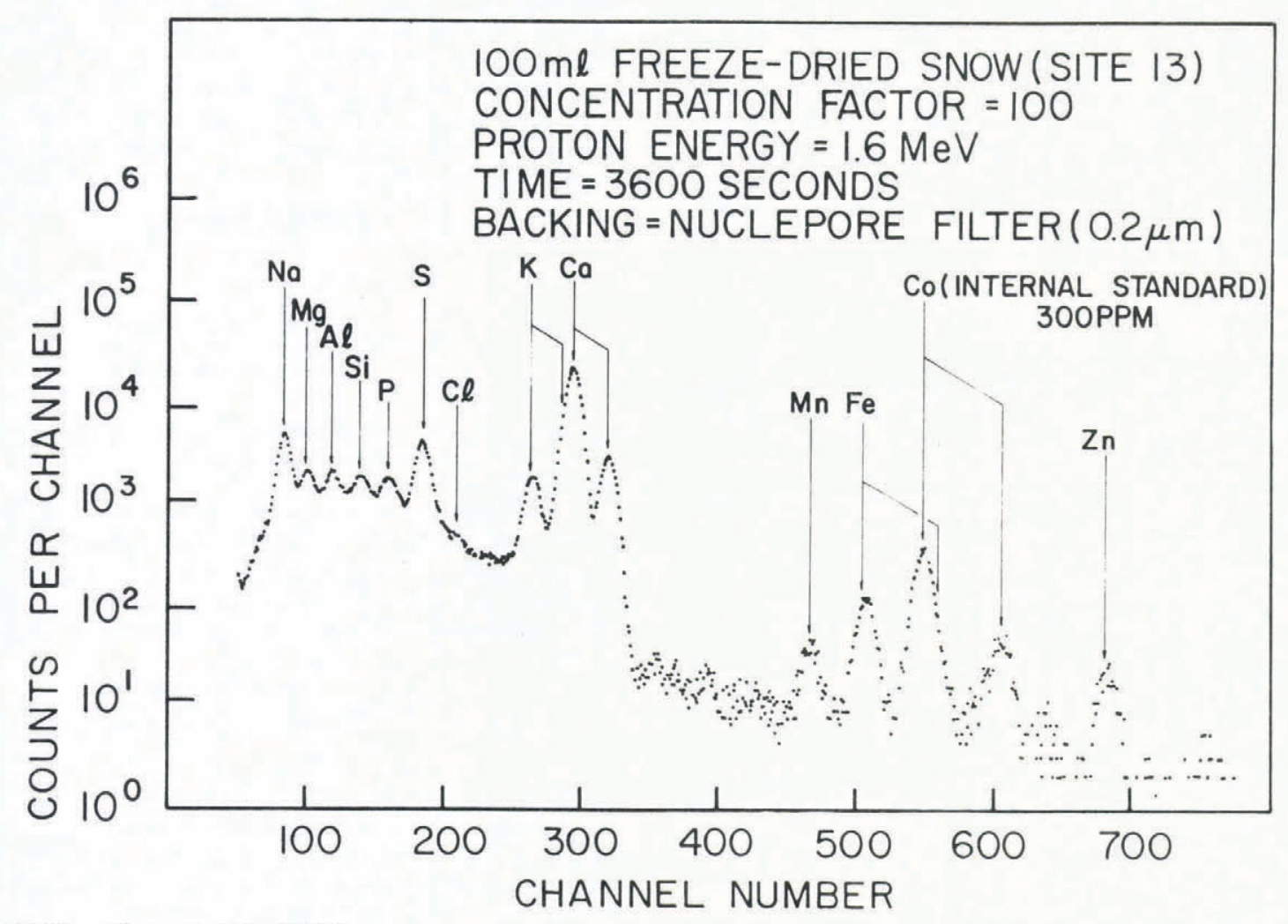

Fig.2. Characteristic PIXE spectrum of snow soluble portion at $1.6 \mathrm{MeV}$ (Landsberger and others 1983[a]).

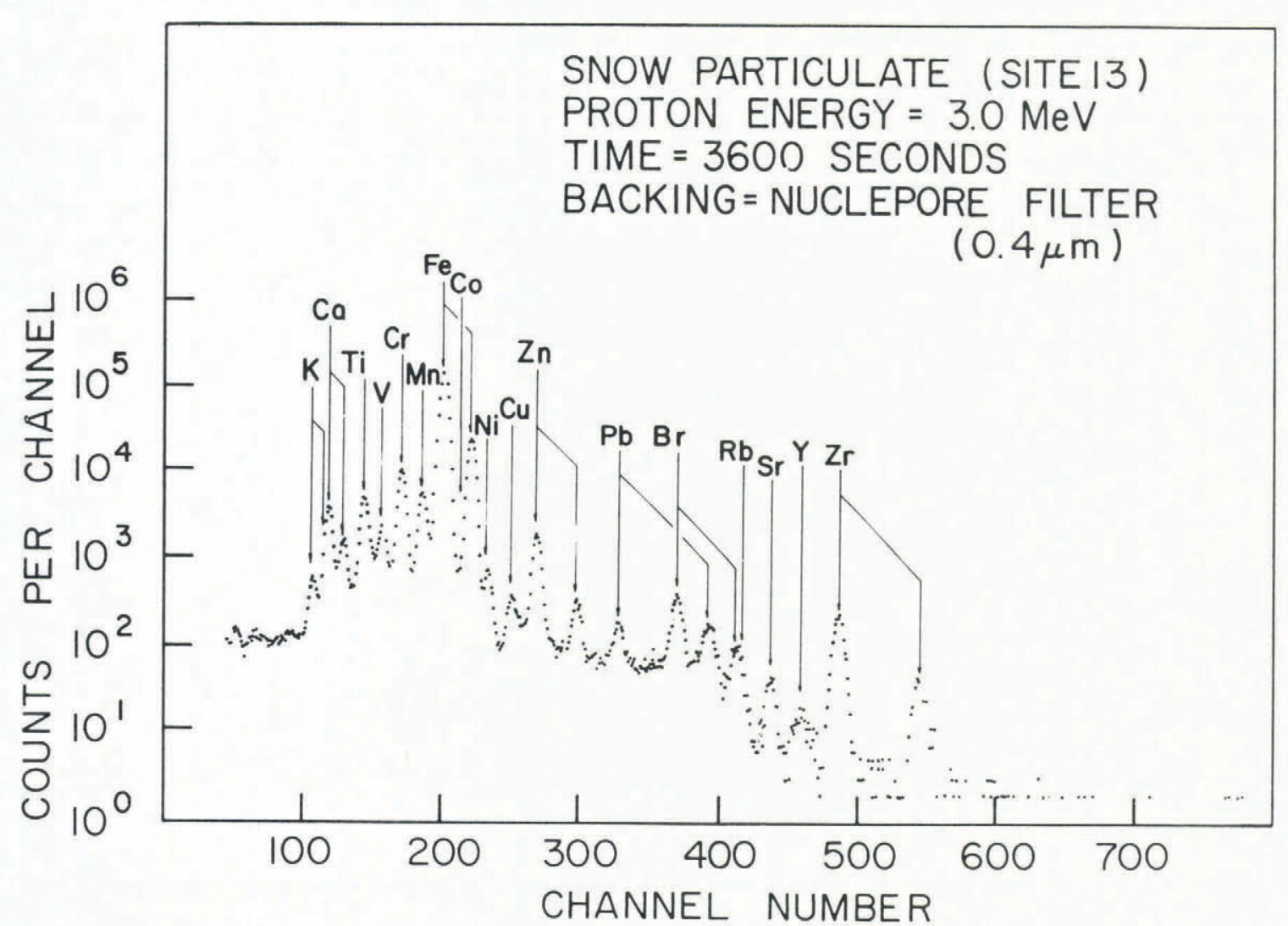

Fig.3. Characteristic PIXE spectrum of snow particulate portion at $3.0 \mathrm{MeV}$ (Landsberger and
others 1983[a]). 
2.3. Inductively coupled plasma-atomic emission spectrometry (ICP-AES)

As with PIXE methods, application of ICP-AES to determine sulphur and metals in either rain or snow has not been greatly used. Barnes (1978) has effectively reviewed the analytical techniques of ICP-AES, but it appears that only one study has exploited this powerful technique to determine elements in rain (Schuyster and others 1978). Concentrations and detection limits for 17 elements (Table III) in three Montreal snow sites are presented here for the first time. The analytical accuracy of this method is shown by analyzing the trace elements in water NBS-SRM 1643a (Table IV).

TABLE III. CONCENTRATIONS AND DETECTION LIMITS OF ELEMENTS IN THREE MONTREAL SNOW SITES AS DETERMINED BY ICP-AES

\begin{tabular}{|c|c|c|c|c|c|}
\hline Element & $\begin{array}{l}\text { Site } 1 \\
\left(\mu \mathrm{g}^{-1}\right)\end{array}$ & $\begin{array}{l}\text { Site 2 } \\
\left(\mu \mathrm{g} \mathrm{1^{-1 }}\right)\end{array}$ & $\begin{array}{l}\text { Site } \\
(\mu \mathrm{g}\end{array}$ & $\begin{array}{c}3 \\
\left.1^{-1}\right)\end{array}$ & $\begin{array}{l}\text { Detection limit } \\
\qquad\left(\mu \mathrm{g} 1^{-1}\right)\end{array}$ \\
\hline $\mathrm{Al}$ & $92 \pm 6$ & $506 \pm 23$ & 458 & \pm 8 & 25 \\
\hline As & $<70$ & $<70$ & $<70$ & & 70 \\
\hline $\mathrm{Ca}^{*}$ & $51.6 \pm 1.3$ & $5.9 \pm 0.1$ & 2.2 & \pm 0.1 & 1 \\
\hline $\mathrm{Cd}$ & $<3$ & $6 \pm 2$ & 7 & \pm 2 & 3 \\
\hline $\mathrm{Cr}$ & $<4$ & $9 \pm 1$ & 10 & \pm 2 & 4 \\
\hline $\mathrm{Co}$ & $4 \pm 1$ & $8 \pm 2$ & 7 & \pm 1 & 4 \\
\hline $\mathrm{Cu}$ & $26 \pm 1$ & $62 \pm 2$ & 37 & \pm 1 & 4 \\
\hline $\mathrm{Fe}$ & $10 \pm 1$ & $65 \pm 1$ & 72 & \pm 1 & 2 \\
\hline $\mathrm{Mg}$ & $<20$ & $372 \pm 13$ & 335 & \pm 9 & 20 \\
\hline $\mathrm{Mn}$ & $<5$ & $12 \pm 1$ & 22 & \pm 1 & 5 \\
\hline Mo & $<7$ & $8 \pm 2$ & 12 & \pm 2 & 7 \\
\hline $\mathrm{Ni}$ & $11 \pm 2$ & $70 \pm 4$ & 39 & \pm 3 & 10 \\
\hline $\mathrm{P}$ & $<53$ & $<53$ & 70 & \pm 11 & 53 \\
\hline $\mathrm{Pb}$ & $<50$ & $<50$ & 62 & \pm 17 & 50 \\
\hline $\mathrm{S}$ & $1800 \pm 160$ & $893 \pm 30$ & 2000 & \pm 30 & 4 \\
\hline V & $4 \pm 2$ & $5 \pm 2$ & 2 & \pm 2 & 2 \\
\hline $\mathrm{Zn}$ & $5 \pm 3$ & $161 \pm 3$ & 109 & \pm 3 & 4 \\
\hline
\end{tabular}

* Calcium is shown in parts per million

TABLE IV. CONCENTRATIONS OF ELEMENTS IN WATER NBS-SRM 1643A AS DETERMINED BY ICP-AES

\begin{tabular}{|c|c|c|}
\hline Element & $\begin{array}{l}\text { Measured value* } \\
\left(\mu \mathrm{g}^{-1}\right)\end{array}$ & $\begin{array}{l}\text { NBS value** } \\
\left(\mu \mathrm{g} 1^{-1}\right)\end{array}$ \\
\hline As & $<70$ & $76 \pm 7$ \\
\hline $\mathrm{Cd}$ & $12.2 \pm 1.6$ & $10 \pm 1$ \\
\hline $\mathrm{Cr}$ & $14.2 \pm 3.4$ & $17 \pm 2$ \\
\hline Co & $21.5 \pm 2.0$ & $19 \pm 2$ \\
\hline $\mathrm{Cu}$ & $19.3 \pm 3.1$ & $18 \pm 2$ \\
\hline $\mathrm{Fe}$ & $84.5 \pm 1.8$ & $88 \pm 4$ \\
\hline $\mathrm{Pb}$ & $<50$ & $27 \pm 1$ \\
\hline $\mathrm{Mn}$ & $32.0 \pm 0.7$ & $31 \pm 2$ \\
\hline Mo & $95.6 \pm 3.1$ & $95 \pm 6$ \\
\hline $\mathrm{Ni}$ & $50.4 \pm 6.3$ & $55 \pm 3$ \\
\hline V & $51.1 \pm 4.8$ & $53 \pm 3$ \\
\hline $\mathrm{Zn}$ & $69.7 \pm 2.4$ & $72 \pm 4$ \\
\hline $\mathrm{Ca} * * *$ & $27.6 \pm 0.7$ & $(27)$ \\
\hline $\mathrm{Mg} * * *$ & $9.0 \pm 0.2$ & (8) \\
\hline
\end{tabular}

* Errors based upon the average of three determinations and their respective analytical standard deviations.

** Errors based upon the average of five determinations and their respective analytical standard deviations. All NBS values certified except those in parenthesis.

***Values in $\mu \mathrm{g} \mathrm{g}^{-1}$.

\section{INTERPRETATION OF TRACE CONCENTRATIONS}

$A$ detailed environmental assessment of trace elements in wet atmospheric deposition is beyond the scope of this paper. It has been effectively reviewed by Galloway and others (1982). Below is a list of the more common techniques which could be employed for environmental assessments.

(a). Wash-out factor and dry deposition velocity

Chamberlain (1960) proposed the use of a wash-out factor $\left(\mathrm{W}_{\mathrm{i}}\right)$ and dry deposition velocity factor $\mathrm{V}_{\mathrm{g}}$ which are defined as follows:

$$
\begin{aligned}
& \mathrm{W}_{\mathrm{i}}=\frac{\mathrm{C}_{\mathrm{i}} \text { (precipitation) }}{\mathrm{C}_{\mathrm{i}} \text { (aerosol) }} \\
& \mathrm{V}_{\mathrm{g}}=\frac{\text { rate of dry deposition }}{\text { concentration in air }}
\end{aligned}
$$

where $C_{i}$ is the concentration of the element of interest in rain or snow and in the aerosol.

(b). Enrichment factor

In order to distinguish naturally-occurring elements in precipitation or aerosols from those arising from various types of pollution, Gordon and others (1973) suggested the use of elemental enrichment factors (EF). The enrichment factor of an element is defined as follows:

$$
E F=\frac{(X / C) \text { atmosphere }}{(X / C) \text { Earth's crust }}
$$

where $\mathrm{X}$ and $\mathrm{C}$ are the concentrations of the element of interest and a reference element, respectively. An element found in the atmosphere primarily as a result of natural processes such as wind erosion should exhibit an EF close to unity. An EF value greater than unity should suggest that the element arises predominantly from anthropogenic sources.

A list of trace concentrations and EF values for soluble and insoluble snow fractions are shown in Tables $\mathrm{V}$ and VI (Landsberger and others 1983[a]). Aluminum was used as the reference element.

(c). Inter-elemental correlation

The use of such inter-elemental correlations as

TABLE V. RANGE OF CONCENTRATIONS AND ENRICHMENT FACTORS IN THE SNOW-MELTED PORTION*

$\begin{array}{lll}\text { Element } & \begin{array}{l}\text { Range } \\ \left(\mu \mathrm{g}^{-1}\right)\end{array} \quad \text { Average EF }\end{array}$

$\begin{array}{lrr}\mathrm{Al} & 25-750 & =1 \\ \mathrm{Na} & 2000-21000 & 336 \\ \mathrm{Mg} & 27-650 & 20 \\ \mathrm{P} & 85-2500 & 640 \\ \mathrm{~S} & 310-3500 & 7000 \\ \mathrm{Cl} & 25000-30000 & 30000 \\ \mathrm{~K} & 100-8000 & 80 \\ \mathrm{Ca} & 1000-7500 & 170 \\ \mathrm{Ti} & 2-55 & 7 \\ \mathrm{~V} & 1-21 & 54 \\ \mathrm{Mn} & 3-170 & 27 \\ \mathrm{Fe} & 1-750 & 3 \\ \mathrm{Co} & <1 & <55 \\ \mathrm{Ni} & 2-300 & 1300 \\ \mathrm{Cu} & 1-140 & 1900 \\ \mathrm{Zn} & 5-300 & 3700 \\ \mathrm{Se} & 0-3 & 15000 \\ \mathrm{Br} & 1-30 & 5500 \\ \mathrm{Rb} & 0-4 & 13 \\ \mathrm{Sr} & 3-80 & 50 \\ \mathrm{Cd} & 1-75 & 220000 \\ \mathrm{~Pb} & 1-300 & 2900\end{array}$

* from Landsberger and others (1983[a]). 
TABLE VI, RANGE OF CONCENTRATIONS AND ENRICHMENT FACTORS IN THE SNOW-PARTICULATE PORTION*
Element

Range

( $\mu \mathrm{g}^{-1}$ )
Average EF

$\begin{aligned} 18800 & -45000 \\ 1500 & -8500 \\ 850 & -6000 \\ <150 & \\ 4000 & -12000 \\ 2500 & -15000 \\ 5000 & -12000 \\ 2000 & -25000 \\ 1 & -10 \\ 2000 & -15000 \\ 100 & -3500 \\ 150 & -600 \\ 15000 & -65000 \\ 40 & -150 \\ 100 & -500 \\ 100 & -500 \\ 200 & -20000 \\ <5 & \\ <11 & \\ 2000 & -10000 \\ 14 & -65 \\ 85 & -200 \\ <30 & \\ 4 & -145 \\ 15 & -110 \\ 2 & -16 \\ 250 & -950 \\ & \end{aligned}$

$=1$

0.7

0.6

$<1$

62

60

0.8

0.6

1

1.6

32

1.5

3

18

15

30

170

$<10$

$<400$

4500

1.5

1.5

2500

330

1.5

1.5

90
* from Landsberger and others (1983[a]).

elemental ratios, factor analysis and cluster analysis can contribute to the elucidation of relative contributions from local and distant sources of major pollution. Although these methods have been successfully used in aerosol studies, they have been seldom employed for investigations of wet atmospheric depositions (Gatz 1981).

Some rain studies have employed inter-elemental correlations using the powerful multi-elemental techniques of NAA and PIXE (Chan and others 1976, Merritt 1976, Tanaka and others 1981). However, an in-depth analysis of inter-elemental correlations and cluster analysis of urban snow was carried out by Landsberger and others (1983[a]).

(d). Other environmental analytical interpretations

The preceding interpretations of analytical results are by no means the only ones available to the analytical environmental scientist. Determination of historical trends in deposition, especially in Arctic and Antarctic regions and glaciers, provide a good indication of increasing industrialization by analyzing the different layers of snow. Weiss and others (1978) have found increased concentrations of lead, zinc and sulphate in Greenland.

The technique of mobilization factor (MF) (Lantzy and MacKenzie 1979), defined as:

$$
M F=\frac{\text { emission rate from human sources }}{\text { emission rate from natural sources }},
$$

can also contribute to the understanding of the different rates of emission from natural and anthropogenic sources. Still another technique called toxicity potential (TP) (Thornton unpublished), defined as

$$
\mathrm{TP}=\frac{\text { concentration of metal in wet deposition }}{\text { recommended upper limits for metal concentration }} \text {, }
$$

can give an indication of how wet atmospheric deposition may possibly pollute drinking water.

\section{CONCLUSIONS}

The capability and versatility of these three multi-elemental techniques described here for snow deposition studies cannot be over-emphasized. Detection limits in parts per billion and even parts per trillion can be reached. More effort to improve preconcentration methods along with ICP-AES can also be investigated. The use of ICP-mass spectrometry which is now commercially available will also probably be of great analytical importance, not just in achieving lower detection limits but also in giving some clearer fingerprinting of elemental pollution.

Clearly, improvements can still be made. For instance, a serious shortcoming that should and could be circumvented is the apparent lack of standardized techniques employed by the various research groups. These include sampling techniques, filtration procedures, use of reference standards and interpretation of data.

Snow sampling techniques could be improved to include weekly or monthly collections. The combined use of aerosol and atmospheric precipitation analysis at the same sampling sites could give a much clearer and badly needed overall picture of the competing scavenging processes in the atmosphere.

All these analytical techniques and environmental interpretations have great potential not only for urban snow but also for polar ice and snow samples.

\section{REFERENCES}

Barnes R M 1978 Inductively coupled plasma-atomic emission spectroscopy in air and water pollution analysis. Toxicological and Environmental Chemistry Review 2: $187-208$

Barrie L A 1979 A wintertime investigation of the deposition of pollutants around an isolated power plant in northern Alberta. Downsview, Ontario, Atmospheric Environment Service (Report ARQT-4-78)

Barrie L A 1980 The fate of particulate emissions from an isolated power plant in the oil sands area of western Canada. Annals of the New York Academy of Sciences 338: $434-452$

Barrie L A, Walmsley J L 1978 A study of sulphur dioxide deposition velocities to snow in northern Canada. Atmospheric Environment 12: 2321-2332

Beavington F, Cawse P A 1979 The deposition of trace elements and major nutrients in dust and rainwater in northern Nigeria. Science of the Total Environment 13: 263-274

Bogen J 1974 Trace elements in precipitation and cloud water in the area of Heidelberg measured by instrumental neutron activation analysis. Atmospheric Environment 8: 835-844

Boutron C 1980 Respective influence of global pollution and volcanic eruptions on the past variations of the trace metals content of Antarctic snows since 1880's. Journal of Geophysical Research 85(C12): 7426-7432

Boutron C, Echevin M, Lorius C 1972 Chemistry of polar snows. Estimation of rates of deposition in Antarctica. Geochimica et Cosmochimica Acta 36(9): 1029-1041

Chamberlain A C 1960 Aspects of the deposition of radioactive and other gases and particles. International Journal of Air Pollution 3: 63-68

Chan K C, Cohen B L, Frohliger J O, Shabason L 1976 Pittsburgh rainwater analysis by PIXE. Tellus 28: 24-30

Dovland H, Eliassen A 1976 Dry deposition on a snow surface. Atmospheric Environment 10(9): 783-785

Forland E J, Gjessing Y T 1975 Snow contamination from washout/rainout and dry deposition. Atmospheric Environment 9(3): 339-352

Galloway J N, Thornton J D, Norton S A, Volchok H L, McLean R A N 1982 Trace metals in atmospheric deposition: a review and analysis. Atmospheric Environment 16: 1677-1700

Gatz D F 1981 An urban influence on deposition of sulfate and soluble metals in summer rains. In Shriner D S, Richmond C R, Lindley S E (eds) Atmospheric sulfur deposition; environmental impacts and health effects. Ann Arbor, MI, Ann Arbor Science: 245-261 
Gordon G E, Zoller W H, Gladney E S 1973 Abnormally enriched trace elements in the atmosphere. In Hemphill D D (ed) Trace substances in environmental health. Vol. 7. Columbia MO, University of Missouri: 161-175

Hamilton E P, Chatt A 1982 Determination of trace elements in atmospheric wet precipitation by instrumental neutron activation analysis. Journal of Radioanalytical and Nuclear Chemistry 71: 29-45

Jeffries D S, Snyder W R 1981 Atmospheric deposition of heavy metals in central Ontario. Water, Air and Soil Pollution 15: 127-152

Jervis R E, Landsberger S, Lecomte R, Paradis P, Monaro S 1982 Determination of trace pollutants in urban snow using PIXE techniques. Nuclear Instruments and Methods in Physics Research 193(1-2): 323-329

Jervis R E, Landsberger S, Aufreiter S, Van Loon J C, Lecomte R, Monaro S 1983 Trace elements in wet atmospheric deposition: application and comparison of PIXE, INAA and graphite-furnace AAS techniques. International Journal of Environmental Analytical Chemistry 15(2): 89-106

Johannessen M, Henriksen A 1978 Chemistry of snow meltwater: changes in concentration during melting. Water Resources 14(4): 615-619

Johannessen M, Dale T, Gjessing E T, Henriksen A, Wright R F 1977 Acid precipitation in Norway: the regional distribution of contaminants in snow and the chemical concentration processes during snowmelt. International Association of Hydrological Sciences Publication 118 (General Assembly of Grenoble 1975 Isotopes and Impurities in Snow and Ice): 116-120

Landsberger S, Jervis R E, Kajrys G, Monaro S 1983[a] Characterization of trace elemental pollutants in urban snow using proton induced $\mathrm{X}$-ray emission and instrumental neutron activation analysis. International Journal of Environmental Analytical Chemistry 16(2): 95-130

Landsberger S, Jervis R E, Kajrys G, Monaro S 1983[b] Total sulphur and insoluble sulphur concentrations in urban snow. Environmental Science and Technology 17: $542-546$

Lantzy R J, MacKenzie F T 1979 Atmospheric trace metals: global cycles and assessment of man's impact. Geochimica et Cosmochimica Acta 43: 511-529

Lindberg S E 1981 The relationship between manganese and sulphate ions in rain. Atmospheric Environment 15: 1749-1753

Merritt W F 1976 Trace element content of precipitation in a remote area. Measurement detection and control of environmental pollutants. Proceedings of a symposium. Vienna, 15-19 March 1976. Vienna, International Atomic Energy Agency: 75-87

Moore D I, Gosz J R, White C S 1978 Impact of a ski basin on a mountain watershed. Water, Air and Soil Pollution 10: 81-93

Murozumi M, Chow T J, Patterson C 1969 Chemical concentrations of pollutant lead aerosols, terrestrial dusts and sea salts in Greenland and Antarctic snow strata. Geochimica et Cosmochimica Acta 33(10): 1247-1294

Salmon L 1975 Instrumental neutron activation analysis in environmental studies of trace elements. Harwell, United Kingdom Atomic Energy Authority (AERE-R 7859)

Schrimpff E, Thomas W, Herrmann R 1979 Regional patterns of contaminants (PAH, pesticides and trace metals) in snow of northwest Bavaria and their relationship to human influence and orographic effects. Water, Air and Soil Pollution 11(4): 481-497

Schuyster P, Maenhaut W, Dams R 1978 Instrumental neutron activation of dry atmospheric fall-out and rain water. Analytica Chimica Acta 100: 75-85

Slanina J, Mols J J, Baard J H, Van der Sloot H A, Van Raaphorst J G 1979 Collection and analysis of rainwater; experimental problems and interpretation of results. International Journal of Environmental Analytical Chemistry 7: 161-176

Struempler A W 1976 Trace metals in rain and snow during 1973 at Chadron, Nebraska. Atmospheric Environment 10: 33-37

Tanaka S, Darzi M, Winchester J W 1981 Elemental analysis of soluble and insoluble fractions of rain and surface waters by particle-induced x-ray emission. Environmental Science and Technology 15: 354-357

Thornton J D Unpublished Trace metals and strong acid content of rain/snow in northern Minnesota, land use effects (M Sc thesis, University of Minnesota, Minneapolis, 1981)

Thornton J D, Eisenreich S J, Munger J W, Gorham E 1981 Trace metal and strong acid composition of rain and snow in northern Minnesota. In Eisenreich S J (ed) Atmospheric pollutants in natural waters. Ann Arbor, MI, Ann Arbor Science: 261-284

Weiss H V, Herron M M, Langway C C Jr 1978 Natural enrichment of elements in snow. Nature 274(5669): 352-353

Wright R F, Dovland H 1977 Regional surveys of the chemistry of the snowpack in Norway later winter 1973, 1974, 1975 and 1976. Oslo - Às, SNSF(Sur Nedbørs Virkning på Skog og Fisk) (Research Report 12/77)

Zajac P K, Grodzinska K 1981 Snow contamination by heavy metals and sulphur in Cracow agglomeration (southern Poland). Water, Air and Soil Pollution 17: 269-280 